\title{
A community pharmacy weight management programme: an evaluation of effectiveness
}

\author{
David Morrison ${ }^{1}$, Philip McLoone ${ }^{1 *}$, Naomi Brosnahan², Louise McCombie ${ }^{2}$, Andrea Smith ${ }^{3}$ and Janie Gordon ${ }^{3}$
}

\begin{abstract}
Background: Community pharmacies may offer an accessible way of delivering weight-management programmes but there have been few trials that use clinically significant weight loss outcomes, objective measures of weight and follow-up to 12 months. We aimed to evaluate weight change among patients who used the Counterweight weight management programme delivered by community pharmacies.

Methods: The Counterweight Programme was introduced into community pharmacies in Fife, Scotland in 2009 for patients with a $\mathrm{BMI} \geq 30 \mathrm{~kg} / \mathrm{m}^{2}$ or a $\mathrm{BMI} \geq 28 \mathrm{~kg} / \mathrm{m}^{2}$ with a co-morbidity in localities in which Counterweight was not available at GP practices. The aim was to achieve an energy deficit of 500-600 kcal per day. Counterweight specialist dietitians delivered training, support and patient information materials to community pharmacies. Patient weight was measured by pharmacy staff at each weight management session. Weight data recorded at each weight management session were used to estimate weight change and attendance at 3,6 and 12 months.
\end{abstract}

Results: Between March 2009 and July 2012, 458 patients were enrolled by the community pharmacies. Three-quarters of patients were women, mean age was 54 (SD 7.4) years and mean BMl 36.1 (SD 5.9) kg/m². Of 314 patients enrolled for at least 12 months, 32 (10.2\% on an intention to treat basis) had achieved the target weight loss of $\geq 5 \%$; this was $41.6 \%$ of those who attended at 12 months representing a mean weight loss of $4.1 \mathrm{~kg}$. Using Last Observation Carried Forward, 15.9\% achieved the target weight loss within 12 months of enrolling. There was no significant effect of sex, baseline BMI or age on weight loss.

Conclusions: The Counterweight pharmacy programme has a similar effectiveness to other primary care based weight management programmes and should be considered as part of a range of services available to a community to manage overweight and obesity.

Keywords: Obesity, Weight management, Pharmacy, Counterweight, BMI

\section{Background}

Obesity is an important risk factor for many chronic conditions, such as cardiovascular diseases, cancers and diabetes mellitus [1-3]. The worldwide prevalence of obesity has doubled since 1980 [4]. In the UK it has trebled in the past thirty years and further increases are predicted [5,6]. A range of approaches will be needed to halt the increase in obesity and to reduce its prevalence. These will include primary prevention by engineering public places to promote physical activity and encouraging the avoidance of unhealthy foods [7]. Effective

\footnotetext{
* Correspondence: philip.mcloone@glasgow.ac.uk

'West of Scotland Cancer Surveillance Unit, Public Health Research Group, Institute of Health and Wellbeing, University of Glasgow, Glasgow G12 8RZ, Scotland, UK

Full list of author information is available at the end of the article
}

treatment of overweight and established obesity, however, will also be needed [8]. Several models for providing obesity management in primary care have been reported, including the use of community pharmacies.

It is estimated that $95 \%$ of the population visit a community pharmacy during the year $[9,10]$. Because of this, pharmacies in Scotland have been encouraged to provide a variety of health related services - these have included health assessments for diabetes, cardiovascular diseases, asthma, and smoking cessation [9]. Pharmacies also offer over-the-counter weight loss products [11]. Where pharmacy has been used as one treatment arm in a randomised controlled trial comparing a range of weight reduction programmes, $14 \%$ of pharmacy participants lost at least $5 \%$ of their initial weight although there was

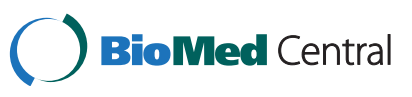


no significant difference in their mean weights at 12 months [12]. A recent systematic review of the effectiveness and cost effectiveness of community pharmacy-based weight management identified 10 initiatives involving 582 pharmacies in 5 countries. The authors of the review found that community pharmacy weight management could produce modest weight loss at 12 months of between 1.1-4.1 kg, but concluded that there was insufficient evidence of effectiveness and cost effectiveness because of limitations in how the studies were carried out and reported [13]. For example, only 3 studies reported longterm (12 month) weight change; only one study employed evidence-based guidelines in its programme; and few reported any cost information. The authors of the review recommended that body weight should be objectively measured and that proportions of patients achieving clinically significant weight loss should be reported alongside mean weight loss to enable comparison of effectiveness from a clinical point of view [13]. The health benefits of clinically significant weight loss, defined as loss of $\geq 5 \%$ baseline weight, include reduced blood pressure, improved glycaemic control, reduction in risk of type 2 diabetes, improved lipid profiles, and reduced osteoarthritis-related disability [14].

Counterweight is a weight management programme that has been evaluated for use in routine National Health Service primary care $[15,16]$. A case series study showed that it achieved clinically significant long-term weight loss in $14 \%$ of all patients at 12 months [16]. The programme was introduced into community pharmacies in the Fife region of Scotland in 2009. Our aim was to evaluate the effectiveness of the Counterweight Programme delivered within community pharmacies, using a primary outcome of clinically significant weight change at 12 months.

\section{Methods}

\section{Counterweight intervention}

The Counterweight weight management programme was provided in the Fife region (population 365,000) as part of the Keep Well project. The Keep Well project encourages 40 to 64 year olds, who live in geographical areas which have been identified as having greatest need, to improve their health. The program targets those individuals at high risk of cardiovascular disease, and offers medical advice and support through enhanced Primary Care services. Between 2008 and 2010, 50 general practices in Fife were engaged in the delivery of the Keep Well project. Patients registered with participating practices who had a $B M I \geq 30 \mathrm{~kg} / \mathrm{m}^{2}$ or a $\mathrm{BMI} \geq 28 \mathrm{~kg} / \mathrm{m}^{2}$ with a co-morbidity and who were assessed as being motivated to lose weight were referred to the Counterweight Programme.
Eighty community pharmacies were approached to determine interest in delivering the Counterweight Programme. Twenty three pharmacies expressed an interest, and 18 were invited because they were located in geographical areas where local general practices did not deliver Counterweight. Sixteen pharmacies subsequently agreed to deliver the programme and received training. Twelve of the participating pharmacies where situated in small urban settlements [17] with between 10,000 to 125,000 inhabitants. The remaining four were located in small towns of 3,000-10,000 people. Participating pharmacies were required to have a private consultation room and time to deliver the intervention. All pharmacies had extended opening hours and offered appointments in the evening and at weekends. Marsden High Capacity Portable Scales (Class III) and Seca Leicester Portable Height Measures were supplied by the NHS Fife Keep Well project to measure weight and height. Scales were calibrated on an annual basis [18]. Counterweight resources (training manuals, desk top flip charts and patient information booklets) were initially funded through the core Counterweight Scottish Government funding. Pharmacies were paid a single commitment fee of $£ 100$ for taking part, plus a payment per patient and payments for the provision of replacement staff while staff were trained. Between March 2009 and May 2010, the payment per patient was $£ 54$, which comprised $£ 30$ for patients attending 1-3 appointments and a further $£ 24$ for patients attending 4 or more appointments. From May 2010 to date these payments rose to $£ 64$ and $£ 40$, respectively.

Specialist dietitians competent in Counterweight Programme delivery conducted two four-hour training sessions and a further 3 hour session after 6 months to consolidate the initial training. Most trained staff were pharmacy assistants rather than pharmacists. It was agreed that pharmacy staff would not sell over-the-counter weight loss medications to patients enrolled in the programme. The specialist dietitians also provided mentoring to all pharmacies.

The Counterweight approach to weight management has been described in detail elsewhere [16]. In brief, pharmacy staff delivered patient education by discussing weight management, and communicating information on behaviour change strategies. The initial interventions involved a prescribed eating plan or a goal-setting approach. The aim was to achieve an energy deficit of 500-600 kcal/day. As patients progressed through the programme, emphasis was increasingly directed to weight loss maintenance and the prevention of weight regain. Patients were asked to commit to nine appointments in 12 months following the initial screening visit. This included six initial appointments (10-30 minutes each) with follow-up visits at 6, 9 and 12 months. The 
total time for one patient to be taken through the full programme was estimated at 130 minutes.

The data collected at each visit were recorded using paper based patient forms. Anonymised patient forms were collated centrally and entered into a bespoke Microsoft Access database. The data were checked for incomplete or inaccurate information. The central database was sent to an independent team at Glasgow University at set time points.

\section{Ethics}

Formal ethical approval was unnecessary as this was an audit of a planned delivery of an existing intervention, no new or untested treatment was being offered, and there was no experimentation. No personally identifiable data were collected and written consent was not required.

\section{Data definitions}

Baseline weight and height were collected when patients attended the first session of the weight loss programme. During the first appointment patients were asked whether they smoked and whether they had diabetes. Their response was recorded as a binary variable (yes/ no). Smoking and diabetes status were recorded because they are relevant factors associated with weight, attendance and weight loss. Weight was measured at each subsequent visit. Weight change was evaluated at 3, 6 and 12 months. The weight measurements used in the evaluation were recorded in kilograms at dates closest to 3, 6 and 12 calendar months from enrolment (within time frames of 6-15 weeks, 15 weeks-9 months, and $9-18$ months respectively). The primary outcome of the study was weight loss of at least $5 \%$ of baseline weight at 12 months.

\section{Statistical methods}

Descriptive statistical methods were used to present change in weight at 3,6 and 12 months. Values are presented as means and 95\% confidence intervals (95\% $\mathrm{CI})$, if not indicated otherwise. We present weight change as absolute weight change and the percentage achieving at least $5 \%$ weight loss. The analyses were carried out separately for patients who attended at each time point, and for all patients assuming that participants for whom weight at follow-up was not available retained their baseline weight (baseline-observationcarried-forward BOCF), and assuming participants retained their last observed weight (last-observationcarried-forward LOCF). BOCF and LOCF were included to enable comparison with other studies, but they are biased methods of imputing missing data [19].

Kruskal-Wallis one way analysis of variance, the chisquare test for differences in proportions and logistic regression were used to examine the association of age, sex, and starting BMI with weight loss and attendance. Age and BMI were employed both as continuous and categorical variables. Age was categorised into 3 groups $(<50,50-59$, and $60+$ years). BMI was categorised as follows $<30,30-<35,35-<40$, and $40+\mathrm{kg} / \mathrm{m}^{2}$. The conventional statistical significance threshold of $5 \%$ was used $(\mathrm{p}<0.05)$. All analyses were conducted with STATA version 11 (StataCorp, CollegeStation, TX, USA).

\section{Results}

Between March 2009 and July 2012, 458 patients were enrolled by 16 community pharmacies. The baseline characteristics of patients are shown in Table 1. Sex, age and BMI were not recorded for $2(0.4 \%), 12(2.6 \%)$ and 6 (1.3\%) patients respectively. Three-quarters of patients were women, mean age was 54 years and mean BMI was $36.0 \mathrm{~kg} / \mathrm{m}^{2}$. One-fifth of patients had a BMI of $40 \mathrm{~kg} / \mathrm{m}^{2}$ or over. Smoking was reported among $14 \%$ of patients. Patients who smoked had a slightly lower mean BMI $34.3 \mathrm{~kg} / \mathrm{m}^{2}$ (95\% CI 33.0, 35.6) than those who reported that they did not smoke $36.6 \mathrm{~kg} / \mathrm{m}^{2}(35.9,37.3)(\mathrm{p}=$ 0.005). One in ten patients reported diabetes. Patients with diabetes had a higher baseline BMI $39.1 \mathrm{~kg} / \mathrm{m}^{2}$ $(37.0,41.2)$ than patients who did not have diabetes $35.8 \mathrm{~kg} / \mathrm{m}^{2}(35.2,36.4)(\mathrm{p}=0.002)$.

Attendance and weight change at 3, 6 and 12 months are shown in Table 2. Of the 458 patients who started Counterweight within the enrolment period, progressively fewer had been in the programme long enough to be eligible to attend at later time points. Attendance declined over time from $56.0 \%$ at 3 months to $24.5 \%$ at 12 months. Of 314 patients enrolled for at least 12 months, $32(10.2 \%)$ had achieved the target weight loss of $\geq 5 \%$. This represents $41.6 \%$ of those who attended at 12 months.

The distribution of weight change at 3, 6 and 12 months is illustrated in Figure 1. Weight change was approximately symmetrically distributed around the mean at 3 and 6 months. At 12 months there was stronger evidence of skew in the distribution; for example 2 patients lost more than $20 \mathrm{kgs}$. There were progressively larger mean weight losses over time, from $2.4 \mathrm{~kg}$ at 3 months to $4.1 \mathrm{~kg}$ at 12 months. At 12 months, 57 patients (74\% of patients who attended, $18 \%$ of all patients) had lost some weight, 15 patients (19\% of patients who attended, $5 \%$ of all patients) had gained weight and 5 (6\% of patients who attended, $2 \%$ of all patients) had no appreciable change in weight since baseline (absolute change $\leq$ $250 \mathrm{~g}$ ). The maximum weight loss was $27 \mathrm{~kg}$ and the maximum weight gain $4.6 \mathrm{~kg}$ at 12 months. Weight change, expressed as a percentage of baseline weight, was similar to absolute weight change because the mean baseline weight was close to $100 \mathrm{~kg}$ (data not shown). 
Table 1 Baseline characteristics of 458 Counterweight patients enrolled in community pharmacies

\begin{tabular}{|c|c|c|c|}
\hline Baseline characteristics & & $\%$ or mean & $\begin{array}{l}\text { Patients }(n=458) \\
\text { ( } n \text { or SD) }\end{array}$ \\
\hline Men $\%$ & & 24.9 & $(114)$ \\
\hline Women $\%$ & & 74.7 & (342) \\
\hline Age mean years (SD) & & 54.0 & (7.4) \\
\hline Weight mean kg (SD) & & 96.4 & (18.3) \\
\hline Starting BMI mean $\mathrm{kg} / \mathrm{m}^{2}(\mathrm{SD})$ & & 36.0 & (5.9) \\
\hline \multirow[t]{5}{*}{ Starting BMI $\mathrm{kg} / \mathrm{m}^{2} \%$} & $<30$ & 9.8 & (45) \\
\hline & $30-34$ & 43.9 & (201) \\
\hline & $35-39$ & 23.8 & (109) \\
\hline & $\geq 40$ & 21.2 & (97) \\
\hline & not recorded & 1.3 & (6) \\
\hline \multirow[t]{2}{*}{ Smoking status\% } & smoker & 14.4 & (66) \\
\hline & not recorded & 18.8 & (86) \\
\hline \multirow[t]{2}{*}{ Diabetes Status\% } & diabetic & 11.6 & (53) \\
\hline & not recorded & 15.7 & (72) \\
\hline
\end{tabular}

A higher percentage of men than women attended at 12 months (Table 3). Attendance increased with age and decreased with increasing BMI but these trends were not statistically significant. Men appeared to lose more weight than women (5.8 kg vs. $3.4 \mathrm{~kg} ; \mathrm{p}=0.66$ - Table 3 ) but there was no difference in clinically significant weight loss $(39 \%$ vs. $43 \% ; \mathrm{p}=0.78)$. A relationship between weight loss and age or BMI was not apparent. Table 3 shows that patients aged 40-49 lost more weight than other age groups while those with a BMI $30-34 \mathrm{~kg} / \mathrm{m}^{2}$ lost the least amount of weight. Statistically significant differences were not found when weight loss was modelled by sex, age and BMI individually ( $\operatorname{sex~} \mathrm{p}=0.66$; age $\mathrm{p}=0.66$; BMI $\mathrm{p}=0.21$ - Table 3 ) or in combination. The percentage achieving $\geq 5 \%$ weight loss similarly did not show statistically significant associations with sex $(\mathrm{p}=0.78)$, age $(\mathrm{p}=0.86)$ or BMI $(\mathrm{p}=0.86)$. Table 3 shows that the imputed measures of mean weight loss (BOCF and LOCF) produced substantially lower estimates of mean weight loss than estimates based only on patients who attended. Both BOCF and LOFC estimates similarly showed non-significant patterns by age and BMI.

Patients who smoked had similar weight loss as patients who did not smoke (Table 4). Patients with diabetes who attended at 12 months appeared to lose less weight compared to patients without diabetes $(1.8 \mathrm{~kg}$ vs. $4.6 \mathrm{~kg}$; $\mathrm{p}=0.24$ - Table 4), but a difference was not apparent when the proportions (LOCF) with clinically significant weight loss were compared ( $15 \%$ vs. $17 \% ; \mathrm{p}=0.78)$. Patients who did not report smoking or diabetes status appeared to be less likely to attend at 12 months $(p=0.07 \& p=0.08$ respectively - Table 4).

Table 2 Weight loss among patients at 3, 6, and 12 months since starting programme

\begin{tabular}{|c|c|c|c|c|}
\hline & & \multicolumn{3}{|c|}{ Time since starting programme } \\
\hline & & 3 months $n=430$ & 6 months $n=395$ & 12 months $n=314$ \\
\hline & & $\%$ or mean ( $\mathrm{n}$ or $95 \% \mathrm{Cl}^{*}$ ) & $\%$ or mean (n or $95 \% \mathrm{Cl}^{*}$ ) & $\%$ or mean $\left(\mathrm{n}\right.$ or $\left.95 \% \mathrm{Cl}^{*}\right)$ \\
\hline Attendance $\%(n)$ & & $56.0(241)$ & $33.7(133)$ & $24.5(77)$ \\
\hline \multirow[t]{3}{*}{ Weight loss mean $\mathrm{kg}(95 \% \mathrm{Cl})$} & Attending patients & $2.4(2.02,2.70)$ & $3.5(2.66,4.25)$ & $4.1(2.83,5.41)$ \\
\hline & $\mathrm{BOCF}^{* *}$ & $1.3(1.10,1.54)$ & $1.2(0.85,1.58)$ & $1.0(0.64,1.38)$ \\
\hline & LOCF*** & $1.3(1.10,1.54)$ & $1.6(1.25,1.89)$ & $1.7(1.31,2.14)$ \\
\hline \multirow[t]{3}{*}{$\geq \mathbf{5} \%$ weight loss $\%\left(95 \% \mathrm{Cl}^{*}\right)$} & Attending patients & $17.0(12.5,22.4)$ & $34.6(26.6,43.3)$ & $41.6(30.4,53.4)$ \\
\hline & $\mathrm{BOCF}^{* *}$ & $9.5(6.9,12.7)$ & $11.6(8.7,15.2)$ & $10.2(7.1,14.1)$ \\
\hline & LOCF*** & $9.5(6.9,12.7)$ & $13.9(10.7,17.7)$ & $15.9(12.1,20.4)$ \\
\hline
\end{tabular}

*95\% confidence interval.

**BOFC - baseline observation carried forward.

***LOFC - last observation carried forward. 


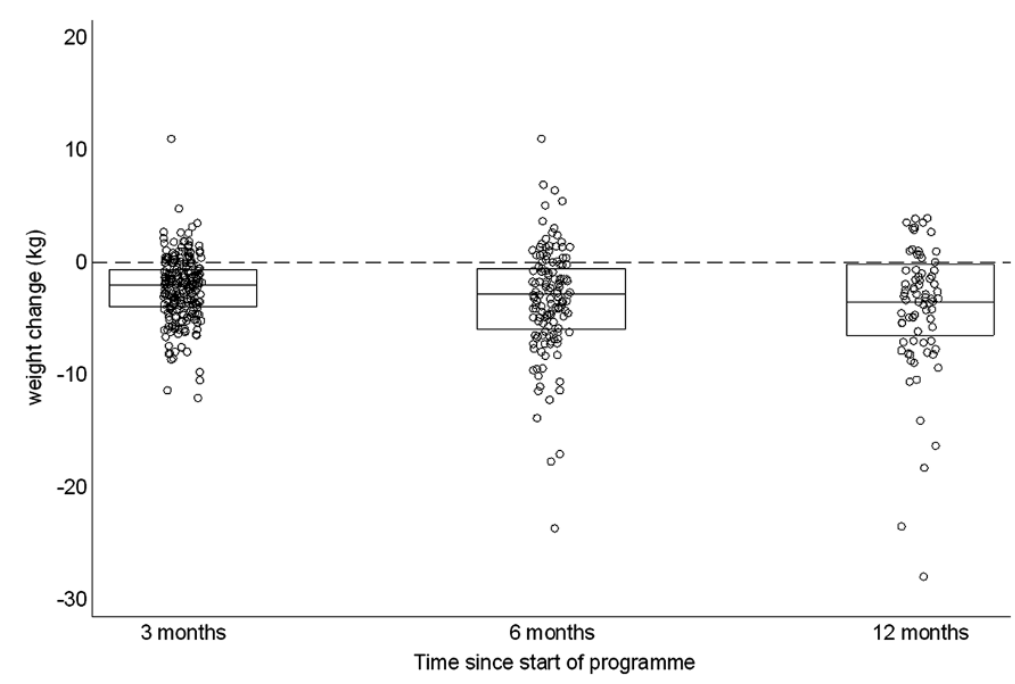

Figure 1 Dot plot comparing weight change at 3, 6, and 12 months since enrollment. Boxes indicate 25th, 50th and 75th percentiles.

\section{Discussion}

Our study reports on the largest prospective evaluation of a pharmacy based weight management programme in the UK over a twelve month follow-up period. We found that $10 \%$ of patients enrolled in a community pharmacy-based weight management programme had lost $\geq 5 \%$ of baseline weight after 12 months. Measurement of successful weight loss maintenance at 12 months requires both initial weight loss and continued attendance and we found that these did not differ significantly by age, sex or baseline BMI. Attendance was highest among men, and appeared to increase with age and decrease with increasing BMI. Weight loss - measurable only among attendees - was greatest in men and patients under 50 but showed no clear relationship to BMI.

Table 3 Weight change and percent of patients achieving $>5 \%$ weight loss at 12 months by sex, age and Body Mass Index

\begin{tabular}{|c|c|c|c|c|c|c|c|c|}
\hline & \multirow[t]{2}{*}{$\begin{array}{l}\text { Number of } \\
\text { patients }\end{array}$} & \multirow{2}{*}{$\begin{array}{l}\text { Percentage } \\
\left(95 \% \mathrm{Cl}^{*}\right) \text { of } \\
\text { patients who } \\
\text { attended }\end{array}$} & \multicolumn{3}{|c|}{ Mean $\left(95 \% \mathrm{Cl}^{*}\right)$ weight loss $(\mathrm{kg})$} & \multicolumn{3}{|c|}{$\begin{array}{l}\text { Percentage }\left(95 \% \mathrm{Cl}^{*}\right) \text { of patients } \\
\text { losing } \geq 5 \% \text { of baseline weight }\end{array}$} \\
\hline & & & $\begin{array}{l}\text { Attending } \\
\text { patients }\end{array}$ & BOCF** & LOCF *** & $\begin{array}{l}\text { Attending } \\
\text { patients }\end{array}$ & BOCF** & LOCF $^{* * *}$ \\
\hline \multicolumn{9}{|l|}{ Sex } \\
\hline Men & 79 & $29.1(19.4,40.4)$ & $5.79(2.47,9.10)$ & $1.69(0.58,2.79)$ & $2.53(1.41,3.56)$ & $39.1(19.7,61.5)$ & $9.8(6.3,14.4)$ & $17.7(10.0,27.9)$ \\
\hline Women & 234 & $23.1(1.78,29.0)$ & $3.41(2.25,4.57)$ & $0.79(0.47,1.11)$ & $1.46(1.05,1.86)$ & $42.6(29.2,56.8)$ & $11.4(5.3,20.5)$ & $15.4(11.0,20.7)$ \\
\hline$p$ value & & 0.28 & 0.66 & 0.62 & 0.21 & 0.78 & 0.69 & 0.62 \\
\hline \multicolumn{9}{|l|}{$\begin{array}{l}\text { Age group } \\
\text { (years) }\end{array}$} \\
\hline $40-49$ & 61 & $19.7(10.6,31.8)$ & $4.78(1.50,8.06)$ & $0.94(0.16,1.72)$ & $1.49(0.56,2.43)$ & $50.0(21.1,78.9)$ & $9.8(3.7,20.2)$ & $16.4(8.2,28.1)$ \\
\hline $50-59$ & 134 & $24.6(17.6,32.8)$ & $3.50(1.40,5.59)$ & $0.86(0.30,1.43)$ & $1.66(1.01,2.32)$ & $39.4(22.9,57.9)$ & $9.7(5.3,16.0)$ & $15.7(10.0,23.0)$ \\
\hline $60+$ & 111 & $27.9(19.8,37.2)$ & $4.29(2.36,6.22)$ & $1.20(0.56,1.84)$ & $1.91(1.22,2.61)$ & $38.7(21.8,57.8)$ & $10.8(5.7,18.1)$ & $16.2(9.9,24.4)$ \\
\hline$p$ value & & 0.49 & 0.66 & 0.77 & 0.57 & 0.78 & 0.96 & 0.99 \\
\hline \multicolumn{9}{|c|}{$\begin{array}{l}\text { BMI grouping } \\
\left(\mathrm{kg} / \mathrm{m}^{2}\right)\end{array}$} \\
\hline$<30$ & 30 & $26.7(12.3,45.9)$ & $5.37(2.35,8.38)$ & $1.43(0.24,2.63)$ & $2.02(0.78,3.25)$ & $75.0(34.9,96.8)$ & $20.0(7.7,38.6)$ & $23.3(9.9,42.3)$ \\
\hline $30-<35$ & 136 & $25.7(18.6,33.9)$ & $2.61(1.35,3.88)$ & $0.67(0.30,1.05)$ & $1.40(0.89,1.91)$ & $37.1(21.5,55.1)$ & $9.6(5.2,15.8)$ & $16.2(10.4,23.5)$ \\
\hline $35-<40$ & 80 & $23.8(14.9,34.6)$ & $3.82(1.09,6.55)$ & $0.91(0.17,1.64)$ & $1.66(0.84,2.48)$ & $31.6(12.6,56.6)$ & $7.5(2.8,15.6)$ & $13.8(7.1,23.3)$ \\
\hline $40+$ & 64 & $23.4(13.8,35.7)$ & $7.35(3.08,11.63)$ & $1.72(0.47,2.98)$ & $2.39(1.08,3.70)$ & $46.7(21.3,73.4)$ & $10.9(4.5,21.2)$ & $15.6(7.8,26.9)$ \\
\hline$p$ value & & 0.97 & 0.21 & 0.74 & 0.91 & 0.18 & 0.28 & 0.68 \\
\hline
\end{tabular}

*95\% confidence interval. **BOFC - baseline observation carried forward. ***LOFC - last observation carried forward. 


\begin{tabular}{|c|c|c|c|c|c|c|}
\hline & & $\begin{array}{c}\text { Number of } \\
\text { patients }\end{array}$ & $\begin{array}{c}\% \\
\text { attending }\end{array}$ & $\begin{array}{l}\text { Mean } 12 \text { month weight } \\
\text { loss }(\mathrm{kg})\left(95 \% \mathrm{Cl}^{*}\right)\end{array}$ & $\begin{array}{l}\% \text { losing } 5 \% \text { weight } \\
\left(\mathrm{BOCF}^{* *}\right)\left(95 \% \mathrm{Cl}^{*}\right)\end{array}$ & $\begin{array}{l}\% \text { losing 5\% weight } \\
\text { (LOCF**) }\left(95 \% \mathrm{Cl}^{*}\right)\end{array}$ \\
\hline \multirow[t]{4}{*}{ Smoking status } & smokers & 45 & 28.9 & $4.47(0.60,8.35)$ & $11(4,24)$ & $13(5,27)$ \\
\hline & non smokers & 210 & 26.2 & $4.19(2.60,5.79)$ & $11(7,16)$ & $17(12,22)$ \\
\hline & not recorded & 59 & 15.3 & $3.16(0.69,5.63)$ & $7(2,16)$ & $15(7,27)$ \\
\hline & $p$ value & & 0.17 & 0.99 & 0.63 & 0.85 \\
\hline \multirow[t]{4}{*}{ Diabetes status } & diabetes & 33 & 21.2 & $1.78(-0.80,4.34)$ & $3(0,16)$ & $15(5,32)$ \\
\hline & no diabetes & 228 & 27.2 & $4.57(3.02,6.13)$ & $12(8,17)$ & $17(12,23)$ \\
\hline & not recorded & 53 & 15.1 & $2.66(0.12,5.12)$ & $6(1,16)$ & $11(4,23)$ \\
\hline & $p$ value & & 0.16 & 0.36 & 0.13 & 0.58 \\
\hline
\end{tabular}

*95\% confidence interval.

**BOCF - baseline observation carried forward.

***LOFC - last observation carried forward.

Jolly's randomised controlled trial, Lighten Up, reported mean weight losses of $1.19 \mathrm{~kg}$ (95\% CI -0.7 to 3.1 ), corresponding to $14.3 \%$ of the cohort (using BOCF) losing $\geq 5 \%$ at one year among users of a pharmacybased weight management programme [12]. Weight losses in our pharmacy trial were similar, with mean loss at 12 months of $1.01 \mathrm{~kg}(0.64,1.38)$ (BOCF) but the proportion achieving a $\geq 5 \%$ loss was lower, at $10.2 \%$. Lighten Up pharmacy patients had lower baseline BMIs than our pharmacy group ( $96 \%$ vs. $78 \%$ respectively with BMI < 40), they were younger (mean age 49 vs. 54 years) but a similar proportion were men ( $27 \%$ vs. $25 \%)$. As we did not find significant effects of either BMI or age on weight loss, it seems unlikely that these explain the observed difference in outcomes. However, $20 \%$ of weights reported in the Lighten Up pharmacy group were self-reported and weights were available for $57 \%$ of patients, compared to our $25 \%$. It would seem that the community pharmacies delivering the Counterweight Programme were poorer at retaining patients but more effective in achieving clinically meaningful weight losses among those who attended. Assessment of readiness to change, for example the stages of change model by Prochaska [20], is widely used in health promotion interventions and is part of the Counterweight Programme. Such information was not collected as part of routine data recording in our study. Improved screening with regular review of motivation may improve retention and efficacy of the programme. Among the three pharmacy studies identified by Gordon and others that reported 12-month outcomes [13], one reported mean weight losses of up to $2.4 \mathrm{~kg}(2.7 \%)$ with the addition of high risk counselling [21]; another reported $1.9 \mathrm{~kg}$ mean weight loss [22]; and a third reported mean weight loss of $4.1 \mathrm{~kg}[23,24]$. Toubro and others' study [23], however, used baseline and subsequent self-reported weights only, and is possibly affected by reporting bias.
Evidence-based weight loss programmes for adults in the UK report 12 month mean weight loss ranging from 1.1 to $6.6 \mathrm{~kg}$, and they achieve 5\% weight loss for between $14 \%$ to $46 \%$ of patients [25]. Commercial communitybased organizations such as Weight-Watchers appear to be more effective [26], but a direct comparisons between programmes is difficult because of differences in the casemix of patients they serve and the context in which the programmes are delivered. All programmes suffer from high attrition which limits the ability to compare outcome data. Effective ways to increase retention and attendance are needed, and this may improve weight loss outcomes by increasing the time spent in programme participation. Weight loss programmes based within community pharmacies have the attraction of being widely accessible which may increase participation. Our study, however, found that when the Counterweight Programme was based in pharmacies, attendance at 12 months was comparable to that achieved when the programme was delivered in general practice ( $25 \%$ vs. $28 \%$ ) [27].

Our study has several strengths and weaknesses. Its strengths are that it reports weight loss using a clinicallybased threshold of $\geq 5 \%$ rather than a mean weight change in a patient group; weights were objectively measured and not self-reported; and that it describes long-term weight loss rather than end-of-programme results. Weaknesses of the study include possible unrepresentativeness of the patients or pharmacies and a lack of detailed information about other social and clinical factors that may have influenced patients' attendance and weight loss. The Keep Well population, for example, is composed of patients from disadvantaged areas, identified at being at high risk of ill health, and who are not fully engaged with primary care services. The present study was not an RCT and we did not employ a comparison group. It is difficult to recruit (particularly to a control group) and conduct such a study when pharmacies were the main delivery point of 
the weight management programme in localities where the study population was composed mainly of patients from disadvantaged backgrounds.

In established practice the Counterweight Programme delivered in primary care achieved $\geq 5 \%$ weight loss at 12 months in $10 \%$ of patients [27] and this Counterweight Programme delivered in pharmacies also achieved the same weight loss in $10 \%$ of patients. Our study indicates the effectiveness of a programme delivered in areas where GPs would not provide Counterweight services and we therefore suggest that pharmacy-delivered weight management remains an option that should be considered where alternatives are not available.

\section{Conclusions}

In conclusion, we have demonstrated that a pharmacybased weight management programme achieves clinically significant, objectively-measured weight losses at 12 months in $10 \%$ of patients who enrol. There are few other evaluations of long-term weight loss outcomes in community pharmacies and several include self-reported weights, which may be subject to significant reporting biases. The Counterweight Programme delivered in pharmacies should be considered as part of a range of services available to a community to manage overweight and obesity.

\section{Competing interests}

LM and NB are employees and shareholders of Counterweight Ltd. The other authors have declared no competing interests.

\section{Authors' contributions}

DM \& PM were responsible for the statistical analyses and drafting and writing the manuscript. AS, JG, LM and NB arranged and coordinated pharmacy involvement, data acquisition and contributed to the drafting of the paper. All authors read and approved the final manuscript.

\section{Acknowledgements}

The intervention was conducted during the Scottish Government Health Department funding of the Counterweight weight management programme in primary care. The pharmacy delivery of the Counterweight Programme was funded through the NHS Fife Keep Well project. The manuscript was produced on behalf of the Counterweight Research Group: J lain Broom, Nick Finer, Gary S Frost, David W Haslam, Sudhesh Kumar, Michael EJ Lean, E Louise McCombie, Philip McLoone, David S Morrison, John PD Reckless, Hazel M Ross and Billy Sloan who contributed to the study design and commented on drafts of the manuscript

\section{Author details \\ ${ }^{1}$ West of Scotland Cancer Surveillance Unit, Public Health Research Group, Institute of Health and Wellbeing, University of Glasgow, Glasgow G12 8RZ, Scotland, UK. ${ }^{2}$ Counterweight Ltd, c/o Brodies LLP, 15 Atholl Crescent, Edinburgh EH3 $8 \mathrm{HA}$, Scotland, UK. ${ }^{3} \mathrm{NHS}$ Fife, Pentland House, Lynebank Hospital, Halbeath Road, Dunfermline KL11 8JH, Scotland, UK.}

Received: 21 September 2012 Accepted: 15 March 2013 Published: 27 March 2013

\section{References}

1. Romero-Corral A, Montori VM, Somers VK, Korinek J, Thomas RJ, Allison TG, Mookadam F, Lopez-Jimenez F: Association of bodyweight with total mortality and with cardiovascular events in coronary artery disease: a systematic review of cohort studies. Lancet 2006, 368:666-678.
2. World Cancer Research Fund/American Institute for Cancer Research: Food Nutrition, Physical Activity, and the Prevention of Cancer: a Global Perspective. Washington DC: AICR; 2007

3. Chan JM, Rimm EB, Colditz GA, Stampfer MJ, Willett WC: Obesity, fat distribution and weight gain as risk factors for clinical diabetes. Diabetes Care 1994, 17:961-969.

4. World Health Organisation: Obesity and overweight Fact Sheet No. 311. Geneva: WHO; 2012. http://www.who.int/mediacentre/factsheets/fs311/en/ (accessed 2 January 2013).

5. Campbell I: The obesity epidemic: can we turn the tide? Heart 2003, 89 (Suppl 2):ii22-ii24.

6. Zaninotto P, Head J, Stamatakis E, Wardle H, Mindell J: Trends in obesity among adults in England from 1993 to 2004 by age and social class and projections of prevalence to 2012. J Epidemiol Community Health 2009, 63:140-146.

7. Butland B, Jebb SA, Kopelman PG, McPherson K, Thomas S, Mardell J, Parry V: Tackling obesities: future choices - project report. London: Government Office for Science; 2007.

8. NICE: Clinical Guideline 43 - Obesity: guidance on the prevention, identification, assessment and management of overweight and obesity in adults and children. London: National Institute for Clinical Excellence; 2006.

9. Scottish Executive: The Right Medicine: A Strategy for Pharmaceutical Care in Scotland. Edinburgh: Scottish Executive; 2002. http://www.scotland.gov.uk/ Resource/Doc/158742/0043086.pdf (accessed 8 August 2012).

10. Scottish Government: Better Health, Better Care: action plan. Edinburgh: NHS Scotland; 2007. http://www.scotland.gov.uk/Resource/Doc/206458/0054871. pdf (accessed 8 August 2012).

11. Andronicou AM, Krska J, Hackett A, Richards J: Supply of over-the-counter weight-loss products from community pharmacies. Int J Pharm Pract 2009, 17:333-337.

12. Jolly K, Lewis A, Beach J, Denley J, Adab P, Deeks JJ, Daley A, Aveyard P: Comparison of range of commercial or primary care led weight reduction programmes with minimal intervention control for weight loss in obesity: Lighten Up randomised controlled trial. BMJ 2011, 343:d6500.

13. Gordon J, Watson M, Avenell A: Lightening the load? A systematic review of community pharmacy-based weight management interventions. Obes Rev 2011, 12:897-911.

14. SIGN: Management of Obesity: A national clinical guideline, number 115, Volume 115. Edinburgh: Scottish Intercollegiate Guidelines Network; 2010. http://www.sign.ac.uk/guidelines/fulltext/115/index.html (accessed 22 August 2012).

15. Counterweight Project Team: A new evidence-based model for weight management in primary care: the Counterweight Programme. J Hum Nutr Dietet 2004, 17:191-208.

16. Counterweight Project Team: Evaluation of the Counterweight Programme for obesity management in primary care. Br J Gen Pract 2008, 58:548-554.

17. Scottish Government: Scottish Government Urban/Rural Classification 20092010. Edinburgh: Scottish Government; 2010. http://www.scotland.gov.uk/ Resource/Doc/933/0103167.pdf (accessed 25 July 2012).

18. Russell CA, Elia M: Nutrition screening survey in the UK in 2008: hospitals, care homes and mental health units. Redditch: British Association for Parenteral and Enteral Nutrition; 2009. http://www.bapen.org.uk/pdfs/nsw/ nsw_report2008-09.pdf (accessed 21 January 2013).

19. Barnes SA, Mallinckrodt CH, Lindborg SR, Carter MK: The impact of missing data and how it is handled on the rate of false-positive results in drug development. Pharm Stat 2008, 7:215-225.

20. Prochaska JO, Velicer WF: The Transtheoretical Model of Health Behavior Change. Am J Health Promot 1997, 12:38-48.

21. Botomino A, Bruppacher R, Krahenbuhl S, Hersberger KE: Change of body weight and lifestyle of persons at risk for diabetes after screening and counselling in pharmacies. Pharm World Sci 2008, 30:222-226.

22. Bradley C: A feasibility study of a weight control programme in community pharmacy in Ireland. In PhD thesis: an exploration of the role of community pharmacists in health promotion in Ireland. University of Dublin, School of Pharmacy \& Pharmaceutical Sciences. 2009:129-163. In Gordon J, Watson M, Avenell A: Lightening the load? A systematic review of community pharmacybased weight management interventions. Obes Reviews 2011, 12:897-911.

23. Toubro S, Dahlager L, Hermansen L, Herborg H, Astrup A: Dietary guidelines on obesity at Danish pharmacies. Results of a 12-week course with a 1-year follow-up. Res Group Hum Nutr Frederiksberg Ugeskr Laeger 1999, 161:5308-5313. 
24. Fonnesbæk L, Frøkjær B, Herborg H: Health promotion in community pharmacy. Country report - Denmark. Hillerød: Pharmakon; 2000. http:// www.univie.ac.at/phc/pics/docs/doc84.pdf (accessed 11 July 2012).

25. McCombie L, Lean MEJ, Haslam D, The Counterweight Research Group: Effective UK weight management services for adults. Clin Obes 2012, 2:96-102.

26. Jebb SA, Ahern AL, Olson AD, Aston LM, Holzapfel C, Stoll J, Amann-Gassner U, Simpson AE, Fuller NR, Pearson S, Lau NS, Mander AP, Hauner $H_{\text {, }}$

Caterson ID: Primary care referral to a commercial provider for weight loss treatment versus standard care: a randomised controlled trial. Lancet 2011, 378:1485-1492.

27. Counterweight Project Team: The implementation of the Counterweight Programme in Scotland, UK. Fam Pract 2012, 29(Suppl 1):i139-i144.

\section{doi:10.1186/1471-2458-13-282}

Cite this article as: Morrison et al:: A community pharmacy weight management programme: an evaluation of effectiveness. BMC Public Health 2013 13:282.

\section{Submit your next manuscript to BioMed Central and take full advantage of:}

- Convenient online submission

- Thorough peer review

- No space constraints or color figure charges

- Immediate publication on acceptance

- Inclusion in PubMed, CAS, Scopus and Google Scholar

- Research which is freely available for redistribution 